\title{
$\mathrm{PDE}$ 기반 $\mathrm{PGC}$ 추진기관 시스템 연구 동향
}

김지훈, 김태영, 진완성, 최정열*

\section{Research Activities on PGC Propulsion Systems based on PDE}

Ji-Hoon Kim, Tae-Young Kim, Wan-Sung Jin and Jeong-Yeol Choi*

Department of Aerospace Engineering, Pusan National University

\begin{abstract}
Most of the aerospace propulsion is based on the Brayton cycle, in which the combustion is held through the constant pressure process, but further improvement of performance by increasing compression ratio is challenged by mechanical limits. Detonation propulsions, regarded promising for high-speed propulsion for a lase decade, is more rigorously studied in these days as a game-changer for the improvement of thermodynamic efficiency of propulsion and power generation systems. Since, the additional compression by the strong shock of the detonation wave is considered increasing thermodynamics efficiency that is hardly achievable by the conventional compression systems. Present paper will give an introduction the latest technical trends on the Pulse Detonation Engines(PDEs) and the activities on the Pressure Gain Combustion (PGC) based on Constant Volume Combustion (CVC).
\end{abstract}

\section{초 록}

대부분의 항공우주 추진은 정압 Brayton 사이클에 기초하고 있으나 성능 향상을 위한 압력비 증가는 기계적 한계에 직면하고 있다. 지난 십여 년간 고속 추진에 적합한 연소 방식으로 기대 받은 데토네이션 추진이, 최근에는 추진기관과 동력 장치의 열효율을 획기 적으로 증대시켜 줄 수 있는 "game-changer"로 연구되고 있다. 즉, 데토네이션 파에 수반 하는 강한 충격파의 압축 효과는 기존의 압축 방식에서 얻기 힘든 열효율을 증가시키는 것으로 여겨진다. 본 논문에서는 펄스데토네이션엔진의 최신 기술 동향과 더불어 정적연 소에 기초한 압력증가연소 체계의 연구 동향에 대하여 소개할 것이다.

Key Words : Detonation(데토네이션), Constant Volume Combustion(CVC, 정적 연소), Pressure Gain Combustion(PGC, 압력증가연소), Pulse Detonation Engine(PDE, 펄스데토 네이션엔진), Rotating Detonation Engine(RDE, 회전 데토네이션 엔진)

\section{I. 서 론}

대부분의 항공우주 추진기관은 정압 조건에서 가열이 이루어지는 Brayton 사이클 기반의 모든
개방형 동력 장치의 성능은 압력 비에 의존한다. 그러나 비추력이나 연비 등의 성능 향상을 위하 여 기계적인 방법으로 터보 펌프나 압축기의 단 수나 회전수를 늘려 압축비를 증가시키는 방법은
† Received: June 23, 2014 Accepted: August 22, 2014

* Corresponding author, E-mail : aerochoi@pusan.ac.kr http:/ /journal.ksas.or.kr/

pISSN 1225-1348 / eISSN 2287-6871 
기계적 한계로 더 이상의 성능 향상에 어려움을 겪고 있다.

이러한 어려움을 극복하기 위한 획기적인 방안 으로써, 개방형 동력 장치에서 데토네이션을 이 용하여 연소 과정에서 압력을 증가시킴으로써 정 적 연소 (Constant Volume Combustion, CVC) 의 효과를 얻을 수 있는 압력증가연소 (Pressure Gain Combustion, PGC) 연구가 근래에 들어 다 시 시도되고 있으며, 이를 통하여 정압연소에서 대비 15 30\%의 사이클 효율향상이 기대되고 있 다[1,2]. PGC 연구의 대표적인 사례로는 $\mathrm{PDE}$, $\mathrm{CDE}$ 와 $\mathrm{CVC}$ 사이클에 기반한 엔진을 기존의 터 보제트와 결합한 형태의 복합 사이클 추진기관 등이 있다.

$\mathrm{PDE}$ 와 같은 $\mathrm{CVC}$ 사이클 엔진은 극초음속 영 역에서 램제트 엔진보다 높은 비추력을 가지며, 터빈과 같은 고온 회전 부품이 필수적이지 않기 때문에 극초음속 환경에서의 작동에도 문제가 없 다. 데토네이션 연소 방식을 이용하여 추진기관 의 효율을 증가 시키고자 하는 연구로는 $\mathrm{PDE}$ 이 외에도 $\mathrm{RDE}$, Wave Rotor 등이 연구되고 있지 만, 본 논문에서는 가장 TRL (Technology Readiness Level) 수준이 높은 것으로 여겨지고 있는 $\mathrm{PDE}$ 에 한정하여 추진 기관에 대한 소개와 최근 연구 동향을 소개하고자 한다. 아울러 전 세계적으로 진행되고 있는 PGC 연구 및 가스터 빈 및 로켓 엔진과의 체계 통합 연구 동향에 대 해 논의가 다루어 질 것이다.

\section{II. 데토네이션과 추진기관}

\section{1 아음속화염과 데토네이션}

연소 과정은 아음속화염과 데토네이션 두 가 지의 경우로 진행된다. 아음속화염의 경우 화염 속도가 아음속으로 전파되며 압력과 밀도의 감소 를 유발한다. 반면 데토네이션의 경우 전방에 강 한 충격파를 생성하여 화염이 초음속으로 전파하 며, 반응물의 밀도와 압력이 초기 혼합물보다 높 다. 두 경우 모두 반응물의 온도는 초기 혼합물 보다 높지만, 데토네이션의 경우 압축 효과에 의 하여 반응물의 온도가 아음속 화염의 경우보다 더 높다. 화염 속도의 차이 역시 두 경우 명확하 다. 아음속 층류화염 전파 속도는 $\mathrm{cm} / \mathrm{s}$ 범위이 고, 난류화염이 $\mathrm{m} / \mathrm{s}$ 범위인 반면, 데토네이션의 경우에는 $\mathrm{km} / \mathrm{s}$ 의 속도로 전파된다. 한편 필요 한 점화에너지도 데토네이션의 경우가 아음속화 염의 경우보다 매우 크다[1].

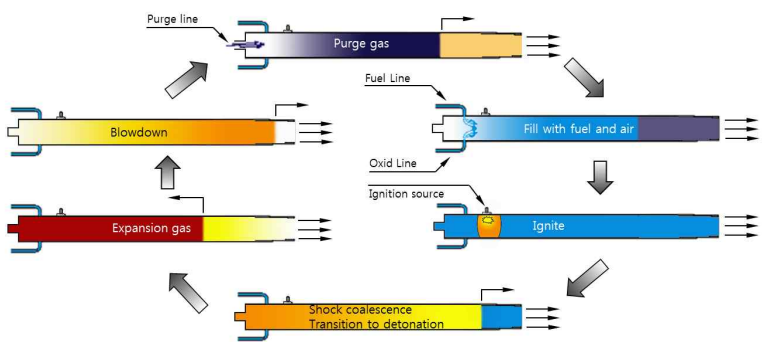

Fig. 1. Operation Cycle of PDE

\subsection{PDE 작동 메커니즘}

$\mathrm{PDE}$ 는 펄스 형태의 데토네이션 파를 직선 관 을 통해 전파시키면서 추력을 얻는 차세대 추진 기관으로, 높은 주파수의 사이클 작동을 통하여 연속적인 추력 발생이 $\mathrm{PDE}$ 엔진의 주요 작동기 구이다. $\mathrm{PDE}$ 의 사이클은 Fig. 1과 같이 먼저 연 료와 산화제가 연소실 내부로 주입이 된다. 추진 제의 공급이 이루어진 후 튜브에 설치된 점화기 를 통해 점화가 이루어진다. 화염이 발생하여 $\mathrm{PDE}$ 튜브 내부에서 전파가 되면서 $\mathrm{DDT}$ (Deflagration to Detonation Transition)가 진행 된다. 데토네이션 파와 연소된 기연 가스가 튜브 외부로 배출되고 난 후 헬륨이나 질소와 같은 비 활성 기체를 연소실에 주입시켜 튜브 내부를 환 기한다. 이상이 한 사이클의 $\mathrm{PDE}$ 작동 과정으로 써, 빠르고 안정적으로 사이클을 반복하는 높은 추진 성능을 얻기 위한 핵심 사항이다.

$\mathrm{PDE}$ 는 주기적 작동 측면에서 펄스제트엔진 (pulse jet engine)과 매우 유사하다. 그러나 아음 속 연소를 이용하는 펄스제트엔진은 압축 메커니 즘이 없으므로, 얻을 수 있는 압력비가 낮아 열 효율 측면에서 더 이상 실용적인 추진기관으로 고려되고 있지 않다. 반면, $\mathrm{PDE}$ 는 데토네이션 충 격파에 의하여 별도의 압축 장치 없이도 높은 압 력비를 얻을 수 있기 때문에 차세대 추진기관으 로 연구되고 있다. $\mathrm{PDE}$ 의 이론 성능 해석에 의 하면 충격파에 의한 전압력손실을 고려하더라도 압축에 의한 효율 향상이 충분히 큰 것으로 여겨 진다[2,3]. 그러나 데토네이션의 직접 발생 (direct initiation)은 매우 큰 에너지를 필요로 하기 때문 에 아음속 연소에 이용되는 일반적인 전기 점화 장치로는 산소를 산화제로 하는 일부 경우를 제 외하고는 실용적이지 않다. 따라서 점화 후 화염 가속(flame acceleration) 후, 천이과정을 거쳐 데 토네이션을 발생 시키는 DDT 과정을 이용하는 것이 일반적이다. 따라서 DDT 과정에 대한 이해 와 함께 Shchelkin spiral과 같이 DDT 가속장치 에 대한 연구도 고주파로 작동하는 $\mathrm{PDE}$ 개발의 
주요 연구과제이다.

$\mathrm{PDE}$ 에서는 기존의 가스터빈엔진에 필요한 압 축기가 필요하지 않기 때문에 비교적 단순한 구 조로 이루어져있다. 따라서 엔진 중량 측면에서 이득을 기대할 수 있으며, 데토네이션의 압축 효 과로 인하여 높은 추력대 중량비를 기대할 수 있 다. $\mathrm{PDE}$ 는 적용 분야에 따라 마이크로 추진기관 부터 실물 엔진 규모의 대형까지 다양한 크기로 연구되었으며, 여러 가지의 추진제로 $10 \quad 100$ $\mathrm{Hz}$ 의 다양한 주파수 작동이 연구되었다. 또한 독자적인 추진기관으로써의 연구뿐 아니라, 가스 터빈엔진의 주 연소기 또는 이차 연소 장치로써 복합추진기관 구성도 연구되고 있다.

\section{3 데토네이션 추진기관 연구 조사}

데토네이션 연소과정에 대한 최초의 열역학 적 이론은 1930년대에 Zel'dovich에 의해 제시되었 으며[4], 2차 세계대전 기간 독일에서 데토네이션 을 추진기관의 연소 메커니즘으로 이용하고자 하 는 연구가 있었다[5]. 2차세계대전후 1950년대에 미국에서 Nicholls 등은 수소-공기의 혼합물을 이 용하여 데토네이션을 발생시켜 추력을 얻은 바 있다[6].

이후 가스터빈 엔진과 로켓 엔진에 연구가 집 중되면서 데토네이션 엔진에 대한 연구는 사장되 었으나, 1980년대에 들어 Eidelman 등이 PDE 추 진기관 개념을 다시 제시하였다[7]. 이후 1990년 대 후반 Bussing 등이 $\mathrm{PDE}$ 작동을 시연하면서 $\mathrm{PDE}$ 관련 연구는 폭발적으로 증가하였다[8]. 지 난 10 여 년간 $\mathrm{PDE}$ 관련 기술은 기초 현상 및, 이론, 요소기술 및 시스템 기술 등 전반적인 분 야에서 상당한 발전을 이루었으며, Kailasanath [9-11], Roy 등[12], 및 Wolanski [13]의 논문에 잘 정리되어 있다. 반면에 국내에서는 1990년대 중반 $\mathrm{PDE}$ 연구가 시작되었으나 제반 여건이 부 족하여 지속되지 못하였다. 최근의 연구는 기초 및 시스템 기술뿐 아니라 점화 장치, 연소기 내 부 장애물 등의 요소 기술에도 비중 있는 연구가 진행되고 있으므로 본 논문에서는 이러한 연구들 의 최신 현황을 갱신하고 미래 전망에 대해 논의 하고자 한다.

\section{$2.4 \mathrm{PGC}$ 와 $\mathrm{PDE}$}

개방형 연소기를 이용하는 가스터빈 엔진 등 모든 동력장치는 Brayton 사이클에 의하여 기술 된다. 가스터빈엔진이 개발된 이후 지난 수십 년 간 많은 연구들이 진행되어 상당히 높은 수준의 효율이 달성되고 있으나, 열, 유체, 구조 및 재료
측면의 제한으로 효율 향상의 기본 요소인 압력 비 증가가 어려워 기계적 한계점을 보이고 있다. Brayton 사이클의 한계를 극복하기 위한 방법으 로, 연소과정 중에 압력 증가를 얻을 수 있는 압 력증가연소(PGC)가 최근 새로이 조명되고 있다.

PGC방식의 가스터빈의 오래된 예로서는 현대 적인 가스터빈이 개발되기 이전에 펄스 방식의 정적연소기를 이용한 1900 년대 초반의 Holzwarth 가스터빈이나[14], 1940년대말 개발된 터보기관과 디젤엔진을 결합한 형태의 Napier Nomad 엔진이 있다[15]. 이러한 시스템들은 복 잡성과 무게로 인하여 새로이 개발된 가스터빈 엔진에 밀려 사장되었다. 21세기에 들어 에너지 효율과 $\mathrm{CO}_{2}$ 배출 저감이 추진기관에도 중요한 문제로 대두되면서, 데토네이션 연소 방식을 이 용하여 개념적으로 간단하고 중량이 가벼운 PGC 방식의 가스터빈을 개발하고자 하는 연구 들이 진행되고 있다.

$\mathrm{PGC}$ 는 연소실의 압력이 공급부의 압력보다 높으므로 개념적으로 정적연소방식과 펄스 방식 의 작동 특징을 가질 수밖에 없는 것으로 여겨진 다. $\mathrm{PDE}$ 의 주기적 작동 특성과 간단한 구조는 PGC연소기에 부합하는 특징으로 데토네이션에 의한 추가적인 압축 효과는 높은 열효율을 기대 할 수 있는 요소이다. 지난 수년간 PDE를 PGC

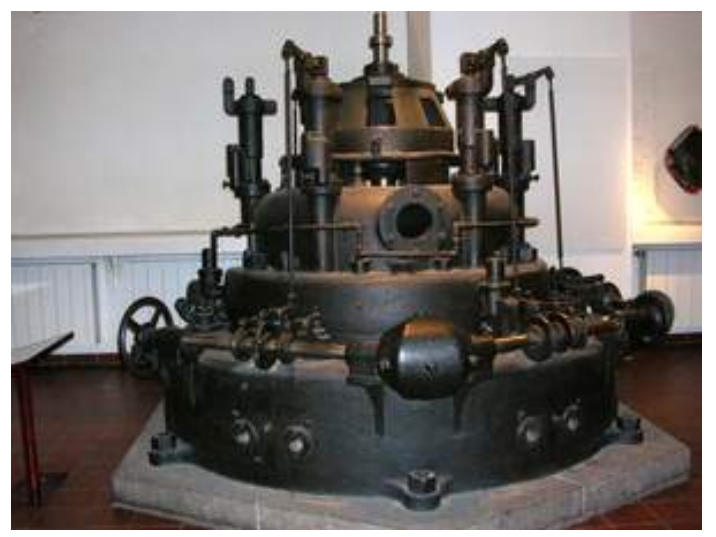

Fig. 2. Holzwarth Experimental Gas Turbine [14]

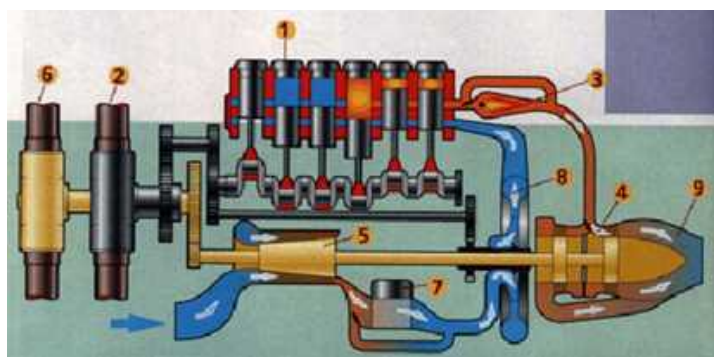

Fig. 3. Napier Nomad I schematics[15] 
방식 가스터빈의 연소기로 이용하고자 하는 여러 노력들이 있었으므로 본 논문에서 이에 대하여 소개하고자 한다. 데토네이션을 이용하는 추진기 관 및 $\mathrm{PGC}$ 연소 방식으로써 $\mathrm{RDE}$ 에 대한 연구가 최근 수년간 진척되고 있으나, 지면 관계로 이에 대한 소개는 별도의 논문으로 다루고자 한다.

\subsection{PGC와 PDE 의 사이클 효율}

PGC 가스터빈의 작동 과정은 단열 압축 후 정적연소를 거쳐 대기압까지 단열 팽창 과정을 거치는 Humphrey 사이클로 기술되므로, 동일한 압축비 또는 압력비를 가지는 Brayton, Diesel 및 Otto 사이클에 비하여 높은 효율을 가질 수 있 다. Fig. 4는 각 사이클과 Humphrey 사이클을 대비한 그림이다. Humphrey 사이클은 Otto 사 이클과 Brayton 사이클에서 각각 손실되는 일을 보존할 수 있으므로, 두 사이클에 비해 더 많은 일을 생산해냄으로써 일의 효율 측면에서 두 사 이클보다 앞선다.

데토네이션 연소 과정은 충격파 압축과 $\mathrm{ZND}$ (Zel'dovich-von Neumann-Döring) 연소과정을 거치므로 Humphrey 사이클의 정적연소 과정과 완전히 동일하지는 않지만 대체로 유사한 특징을 가진다. Fig. 5는 $\mathrm{PDE}$ 사이클을 Humphrey 및 Brayton 사이클과 비교한 그림이고, Fig. 6은 각 사이클의 이론 열효율을 비교한 그림이다. $\mathrm{PDE}$ 사이클은 $\mathrm{CVC}$ 사이클과 매우 유사하지만 다소 높은 효율을 가짐을 알 수 있다. Brayton 사이클 에 비해서는 기계적 압축이 없거나 작은 경우에 는 매우 큰 효율 향상을 기대할 수 있으며, 압축 비가 큰 경우에도 Brayton 사이클에 비하여 수십 $\%$ 이상의 높은 효율을 가짐을 알 수 있다. $\mathrm{PGC}$ 는 엔진의 성능을 매우 큰 폭으로 향상 시 킬 수 있을 것으로 전망할 수 있다.
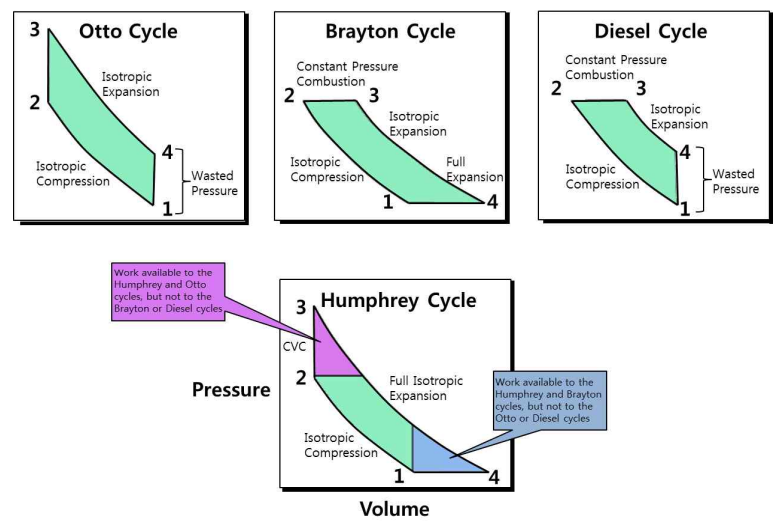

Fig. 4. Comparison of Humphrey Cycle with other Cycles

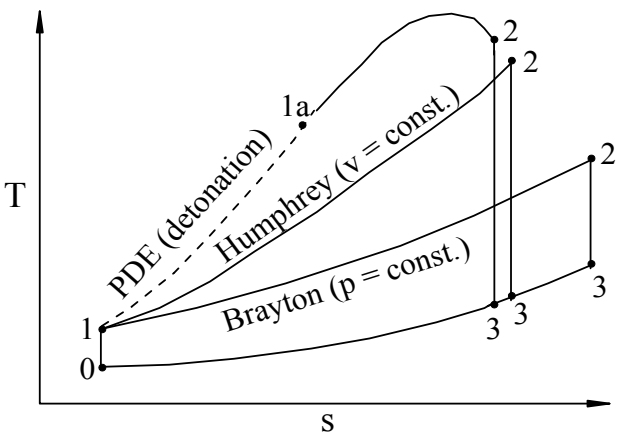

Fig. 5. Temperature - entropy diagram of ideal PDE, Humphrey, and Brayton cycles[3]

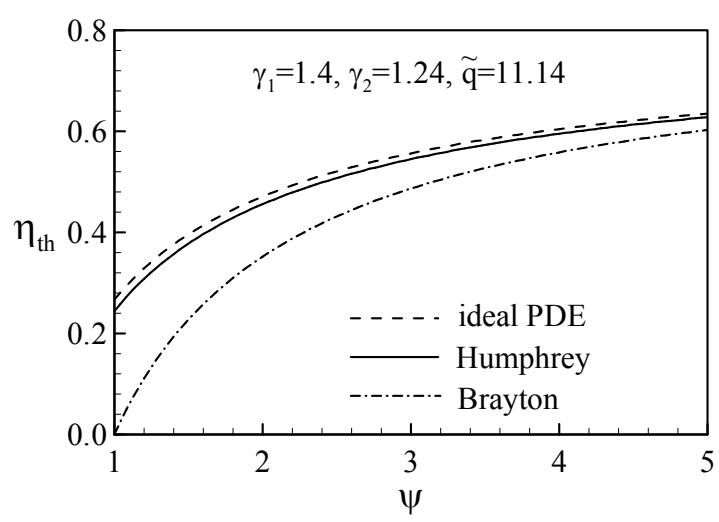

Fig. 6. Performance Comparison between Ideal Humphrey Cycle \& Ideal Brayton Cycle [3]

\section{PDE 시스템 연구 동향}

\section{1 지난 수년간의 주요 연구 성과}

$\mathrm{PDE}$ 개발 연구의 대표적인 성과는 미공군 연 구소의 Schauer 박사팀 주도로 개발한 $\mathrm{PDE}$ 엔진 장착 Long E-Z 유인항공기의 성공적인 비행 시 험이다[16]. Fig. 7은 $\mathrm{PDE}$ 추진 항공기의 동력 비행 시험 사진이다. 이 비행 시험에서 $\mathrm{PDE}$ 추 진 항공기는 약 100 피트 상공에서 짧은 시간 동 력 비행하였지만, 데토네이션이 발생시키는 음압 및 진동이 기체와 조종사 및 지상에서도 모두 감 내할 만한 수준임을 보였으며 그동안 $\mathrm{PDE}$ 에 제 기된 모든 의구심을 해소한 대표적 사례이다.

미국의 $\mathrm{PW}, \mathrm{GE}$ 등의 추진기관 업체에서도 $\mathrm{PDE}$ 엔진 개발 연구가 진행되었다. $\mathrm{PW}$ 에서는 Fig. 8 와 같이 기존의 연소기관을 다중 펄스 데 토네이션 연소기로 대체하는 방법에 대해 연구하 였다[17]. $\mathrm{GE}$ 는 $\mathrm{PDE}$ 를 가스터빈 연소기로 이용 하는 복합 기관에 대해 연구를 수행하였다[18]. 


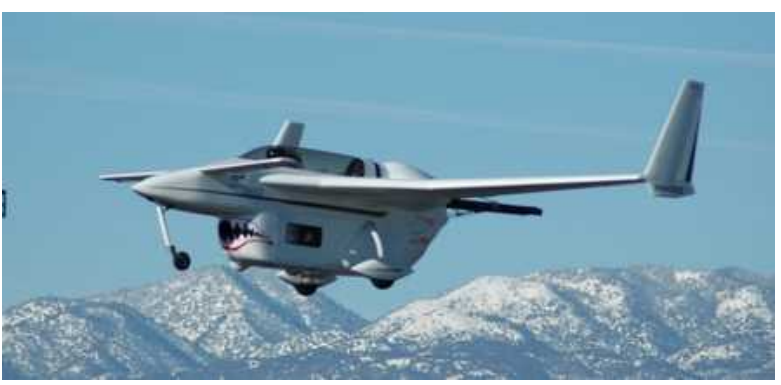

Fig. 7. PDE powered Long E-Z [16]

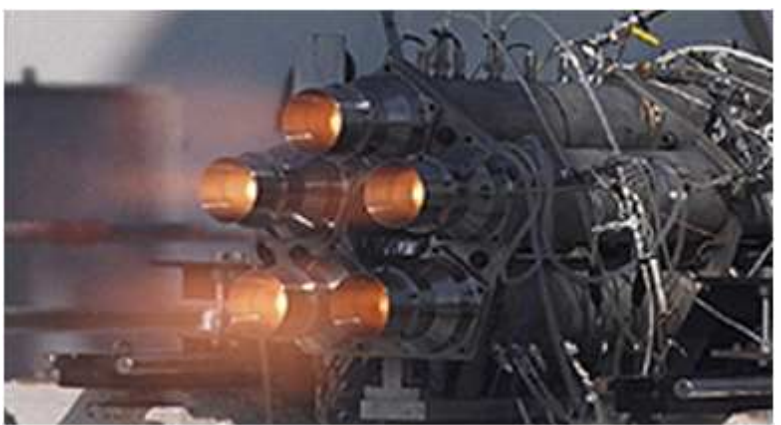

Fig. 8. PW's Multi-PDE Operation[17]

프랑스의 MBDA와 싱가포르의 DSO 국가 연구 소는 $\mathrm{UAV}$ 에 데토네이션 엔진 기술을 적용시키 기 위한 협력 개발을 진행 중이다[19]. 이들의 연 구 목표는 패러볼릭 장애물 (Parabolic obstacles) 를 사용하여 $\mathrm{UAV}$ 이륙 시 점화시기 내에 $\mathrm{SDT}$ (Shock to Detonation Transition)와 DDT (Deflagration to Detonation Transition) 거리를 줄이는 것이다. 또한 $\mathrm{PDE}$ 작동 시 지속적으로 공기를 유입을 위한 통합 흡입구를 연구하고 있 다.

Kojima 등은 수소를 연료로 사용하고 PDE를 주연소기로 사용하는 가스터빈 시스템에 대해 연 구를 수행하였다[20]. 이 연구에서 $\mathrm{PDE}$ 는 엔진출 구에서 약 $65 \%$ 의 엔탈피 강하를 보였으며, 이중 약 $51 \sim 81 \%$ 의 엔탈피 감소가 터빈동력으로 얻어 짐을 보였다. 이들은 또한 공냉식 냉각기가 장착 된 PDRJE(Pulse Detonation Ram Jet Engine)을 극초음속 추진기관으로 제안하였다[21]. PDRJE는 연료 주입 단계에서 연소실이 닫히고, 흡입구에 서 램 압축기가 작동된다. 이들은 PDRJE의 성능 을 평가하기 위해서 $\mathrm{GH}_{2}$ 와 $\mathrm{GOX}$ 의 축소모델을 시험에 이용하였다.

Kasahara 등은 $\mathrm{PDE}$ 와 추진제 탱크, 공급 및 제어계가 완전한 시스템 형태의 $\mathrm{PDRE}(\mathrm{Pulse}$ Detonation Rocket Engine)을 시스템을 구성하여 레일 위를 미끄러지며 이동하는 연구를 진행하였 다. 이들의 연구에서 측정된 추력은 수치적으로
계산된 값에서 $4 \%$ 이내의 정확도를 보였다[22].

\subsection{Vulcan 프로그램}

데토네이션에 관련하여 진행된 기초 연구를 기 반으로 2008년 미국 DARPA에서는 데토네이션 을 기반으로 한 순항 마하수 $4.0+$ 의 실증 엔진 개발을 위해 Vulcan 프로그램을 공고하였다[23]. Vulcan 프로그램은 F- 119 와 같은 기존의 터보엔 진을 기반으로 Fig. 9와 같이 $\mathrm{CVC}$ 엔진을 추가 하여 마하수 4 까지 비행이 가능한 엔진을 개발하 는 프로그램이다. 이 연구의 계기는 소형 비행체 인 HTV-3X의 경우 초음속 크루즈 미사일용 터 보제트 엔진을 사용할 수 있지만, 대형 비행체인 $\mathrm{HCV}$ (Hypersonic Cruise Vehicle)의 경우 높은 초음속 영역까지 작동이 가능한 대형 터보 제트 엔진은 아직 존재하지 않기 때문이다.

높은 마하수에서 작동 가능한 터보 제트 엔진 은 재료의 문제로 인하여 열 차폐 및 냉각, 소재 등에서 기존의 엔진과는 다른 수준의 기술을 요 구하기 때문에, 개발 및 생산 비용 면에서는 비 현실적이다. 따라서 $\mathrm{HCV}$ 에 적용 가능한 $\mathrm{TBCC}$ (Turbine Based Combined Cycle) 통합 체계는 기존에 개발된 군용 터보 팬 엔진과 $\mathrm{CVC}$ 기관 을 결합하여 마하수 4 까지 이용 가능한 형태의 추진 기관이 될 것이다. 또한 마하수 2.5 부터 6 까 지 작동이 가능한 이중 모드 램제트/스크램제트 엔진을 병렬로 연결한 형태가 될 것이다. 이러한 형태의 엔진 제작에 필요한 기술적 문제는 해결 이 가능할 것으로 보여 극초음속 장거리 비행을 위한 추진 체계가 개발 가능할 것으로 전망된다.

하지만 DARPA의 Vulcan 프로그램은 2010년 도부터 2단계로 전환되면서 연구 목표를 높은 개 발 비용과 위험부담이 따르는 항공용 엔진 개발 에서 발전 및 동력 생산 분야에서 실용성을 얻어 내는 방향으로 목표를 수정하였다[24]. 따라서 2 단계에서는 함정용 가스터빈 엔진에 PGC 또는 $\mathrm{CVC}$ 사이클 엔진을 도입하여 연료비를 상당 수 준 절감하는 것을 목표로 설정하였다. 이러한 목 표 수정은 현재의 TRL 수준에 비추어 볼 때 항 공용 엔진 개발보다 현실적으로 가능성이 더욱 높기 때문에 수정한 것으로 여겨진다.

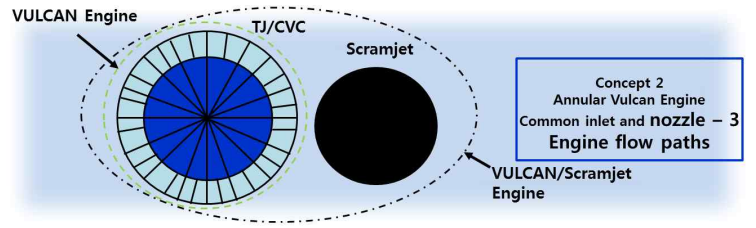

Fig. 9. VULCAN Engine Integration Concept 


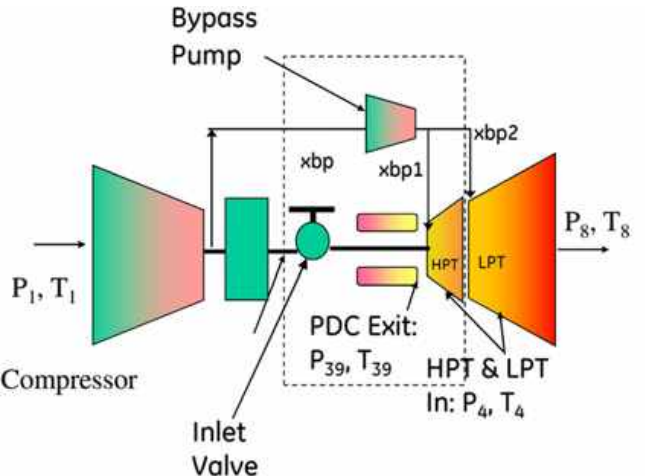

(a)

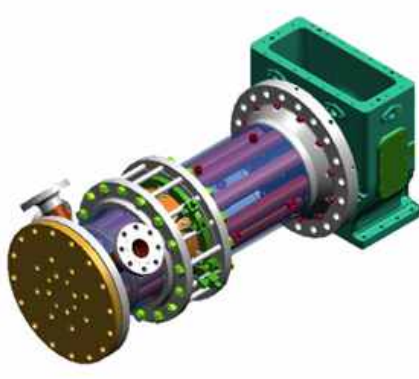

(b)

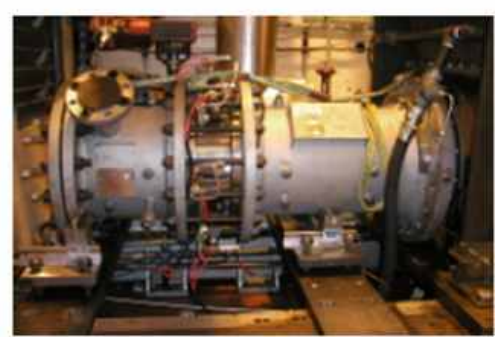

(c)

Fig. 10. (a) Schematic diagram of pressure gain gas-turbine with PDC chamber[25]. (b) computer model of the PDC combustors and (c) picture of the assembled system

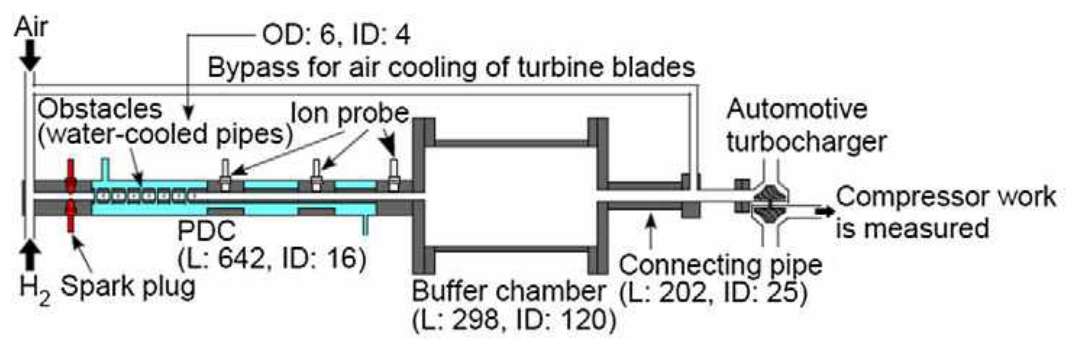

(a)

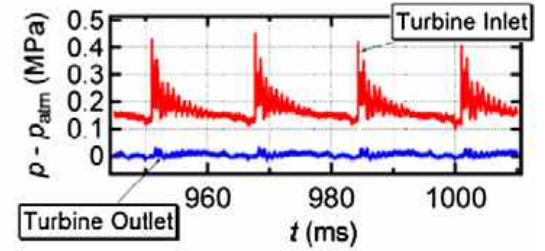

(b)

Fig. 11. Combined PDE and micro gas turbine of Hiroshima university, (a) schematics of system and (b) pressure records before and after turbine[26]

\subsection{PDE-터빈 복합기관}

펄스 데토네이션 연소기 (Pulse Detonation Combustor, PDC)를 기존의 가스터빈 엔진 혹은 터보제트 엔진과 병합한 추진 기관은 추진 기관 자체 혹은 기관이 사용되는 전력 발전소의 효율 을 크게 향상시킬 수 있는 잠재력을 가지고 있 다. GE의 Dean 등은 이러한 기관을 제작하여 성 능을 평가하였다[25]. Fig. 10은 GE의 PGC 가스 터빈 엔진 개략도 및 $\mathrm{PDC}$ 모델이다. 8개의 PDC 튜브가 원형으로 배치되어 $4 \mathrm{~kg} / \mathrm{s}, 25,000 \mathrm{rpm}$, 그리고 $1,000 \mathrm{hp}$ 급의 단식의 축류 터빈과 병합 되어 있다. $\mathrm{PDC}$ 는 최적 당량비의 $C_{2} H_{4}$-공기 혼 합물을 사용하여 $30 \mathrm{~Hz}$ 로 작동하며 유량은 4.5 $\mathrm{kg} / \mathrm{s}$ 였다. 터빈과 압축기는 $18,500 \mathrm{rpm}$ 과 350 마 력으로 작동하였다. PDC 연소 후 압력이 압축기 공급압력 보다 높기 때문에 이 기관에는 기존의 가스터빈 엔진과 차이점이 존재한다. Fig. 10(a) 에서 압축기 후방에 수집부가 있는데, 이는 압축 된 공기를 특수한 밸브를 통해 각각의 PDC 튜 브로 분배하는 역할을 한다. 또한 바이패스 펌프 로 불리는 추가적인 압축기가 존재하는데, 이는 추가적인 공기를 공급하여 $\mathrm{PDC}$ 를 냉각할 뿐 아
니라 PDC로부터 생성되는 데토네이션 반응물에 공기를 추가시키는 기능을 한다. 이러한 이유로, 생성물을 터빈의 첫 단에 적합한 온도 조성을 위 해 플리넘 챔버가 고압 터빈(HPT) 첫 단 전방에 필요하다. 이들의 연구를 통해 충분한 자료가 수 집이 되면 이 시스템의 실제 효율 증가를 평가할 수 있을 것이다.

$\mathrm{PDE}$ 와 터빈의 병합 기술은 대학 연구실 규모 에서도 수행되었다. Fig. 11(a)는 Endo 등에 의하 여 제작된 소형 $\mathrm{PDC}$ 와 터보과급기가 연결된 장 치 개략도이며, Fig. 11(b)는 터빈 입구와 출구에 서 측정된 압력이다[26]. Sakurai 등은 수소를 사 용하는 길이 $200 \mathrm{~mm}$, 부피 $120 \mathrm{~cm}^{3}$ 의 PDC와 1 $\mathrm{kW}$ 급의 소형 가스터빈을 병합하였다[27]. 이들 은 연료 주입의 시각화와 농도 측정을 포함한 시 험 결과 데토네이션이 연소기 내부에서 발생하여 작동 가능성을 확인하였다.

Glaser 등은 축류 터빈과 다중 펄스 데토네이 션 연소기의 병합에 관한 연구를 진행하였다[28]. 이 연구의 주안점은 PDC-터빈 엔진의 성능을 예 측하는 것이다. 이들의 연구에서 엔진의 성능은 터빈 구간에서 생성되는 동력의 양을 측정하여 
수치화하였다. 초기 연구는 정상 상태에서 정압 연소-터빈 엔진과 PDC-터빈 엔진을 비교하였다. 이 방법에 의하여 직접적인 성능 비교와 더불어 축류 터빈과 데토네이션 생성 연소가스의 상호작 용에 대해서도 조사하였다. 이 연구에서 이웃하 는 연소기에서 발생한 데토네이션에 의한 최대 충격 압력은 von Neumann spike 압력의 약 $3 \%$ 에 해당한다는 것을 알 수 있었다. 또한 PDC-터 빈의 효율은 일반적인 가스터빈 기관과 모든 시 스템 작동범위에서 유사한 정도이지만, 일정하지 않은 추진제 주입으로 인해 터빈 효율을 감소한 다고 보고하였다.

\subsection{PDE 로켓}

Kasahara 등은 단일 튜브 PDE 시스템을 이용 하여 Fig. 12의 펄스데토네이션 로켓(PDR) Todoroki를 제작하였다[29]. 제작된 로켓 시스템 은 총 길이가 $2,173 \mathrm{~mm}$, 몸체의 지름은 200 $\mathrm{mm}$, 총 무게는 $24.1 \mathrm{~kg}$ 이다. 로켓의 상부에는

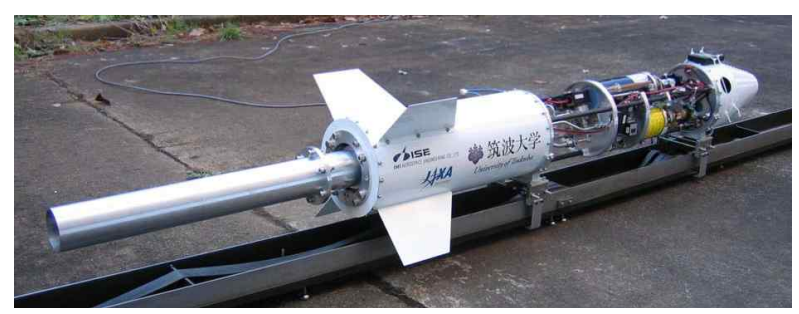

(a) PDRE Todoroki on the guide rail

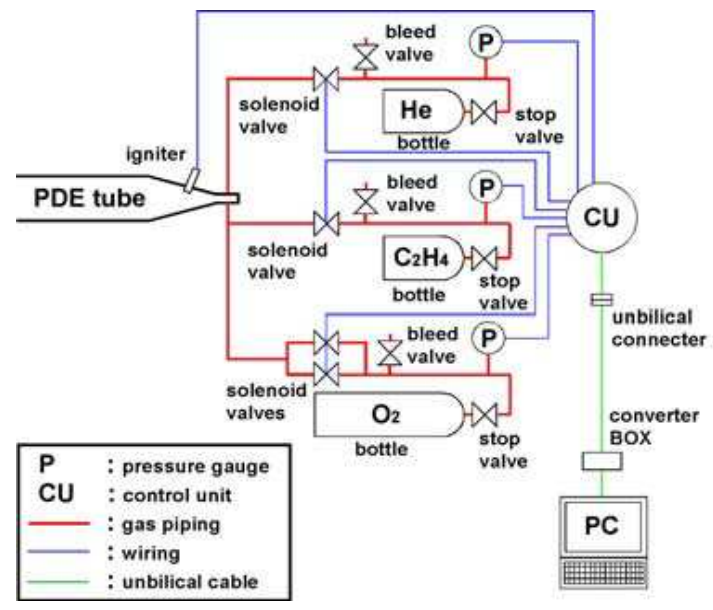

(c) system diagram
제어 시스템이 장착되어 있다. 연료 공급 구간은 4 개의 솔레노이드 밸브로 구성이 되어 있고, 엔 진 구간은 데토네이션 충격으로부터 로켓을 보호 하기 위해 $\mathrm{PDE}$ 튜브와 스프링 감쇠 장치로 구성 이 되어있다. PDR은 4 개의 바퀴를 이용하여 레 일 위를 이동할 수 있는 구조로 제작되었다. 레 일의 길이는 $9 \mathrm{~m}$ 이며 추력은 초기 위치로부터 이동한 거리의 2 차 미분으로부터 도출하였다. 에 틸렌, 산소 및 헬륨은 각각 0.48 리터의 알루미늄 합금 탱크에 채워진다. 제어 구간은 밸브와 점화 기, 그리고 외부의 컴퓨터와 커넥터와 케이블을 통해 연결이 되어 있다. 2초간의 작동 실험에서 에틸렌, 산소, 헬륨의 압력은 각각 $5.2 \mathrm{MPa}, 13.6$ $\mathrm{MPa}, 9.6 \mathrm{MPa}$ 로 유지되었으며 실험과 계산 결 과와 $4 \%$ 이내의 오차를 보였다고 보고하였다. 이 연구는 $\mathrm{PDE}$ 연소기 튜브와 추진제 공급 및 제어 계통을 하나의 시스템으로 구성하여 완전한 형태의 $\mathrm{PDE}$ 엔진을 구현하여 최초로 시연한 것 에 의의를 둘 수 있다.

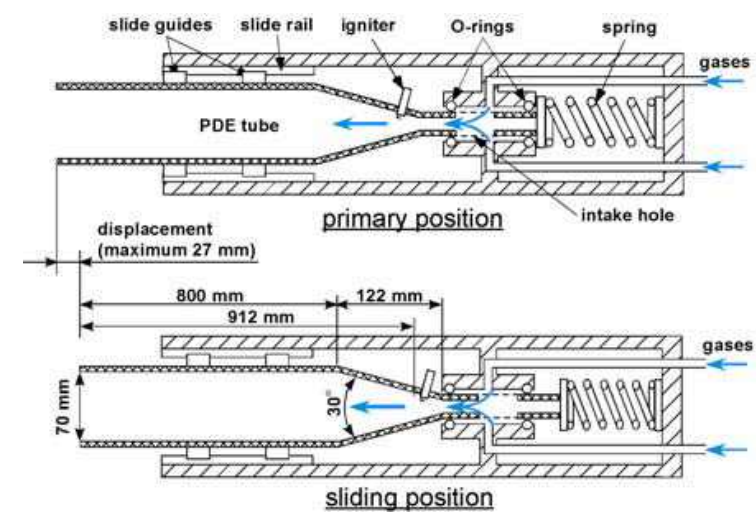

(b) thrust damping mechanism

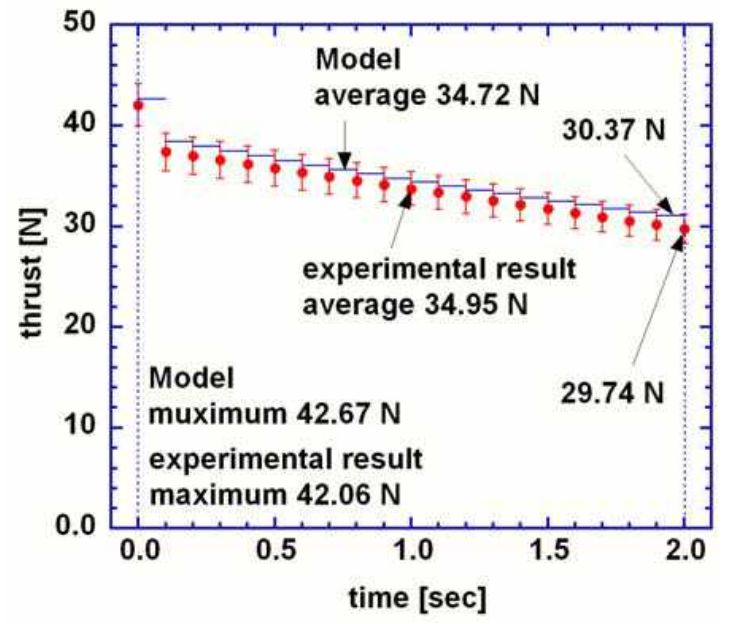

(d) thrust history

Fig. 12. PDR(Pulse Detonation Rocket) Todoroki[29] 


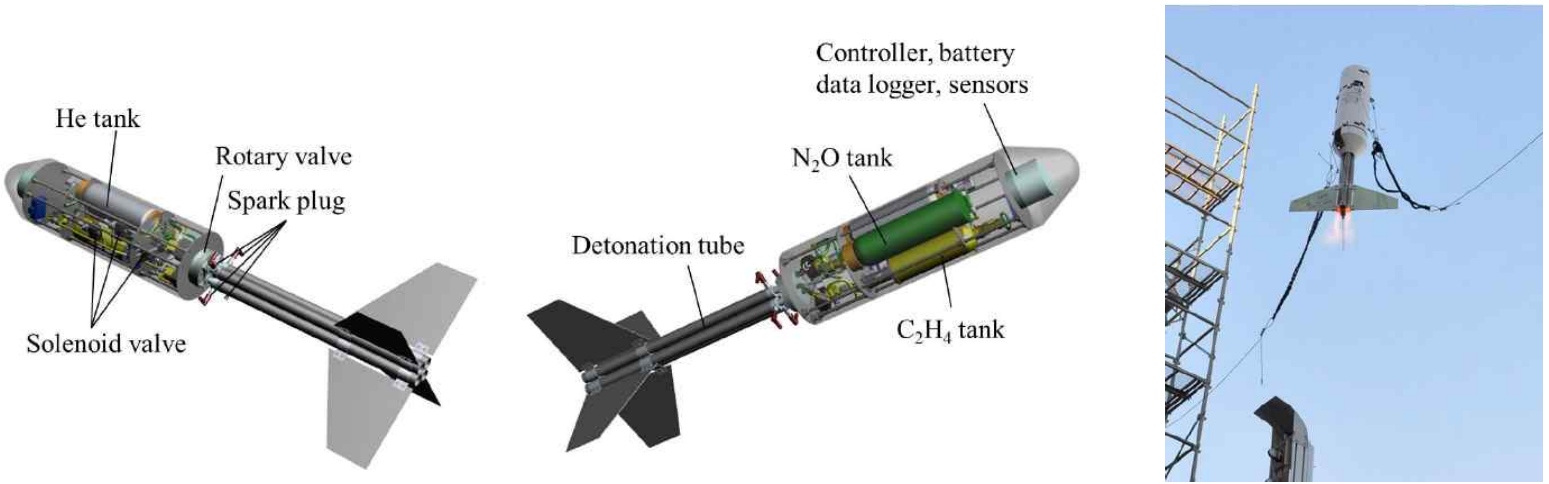

Fig. 13. PDR flight test vehicle: PDR system configurations and PDR in flight [30]

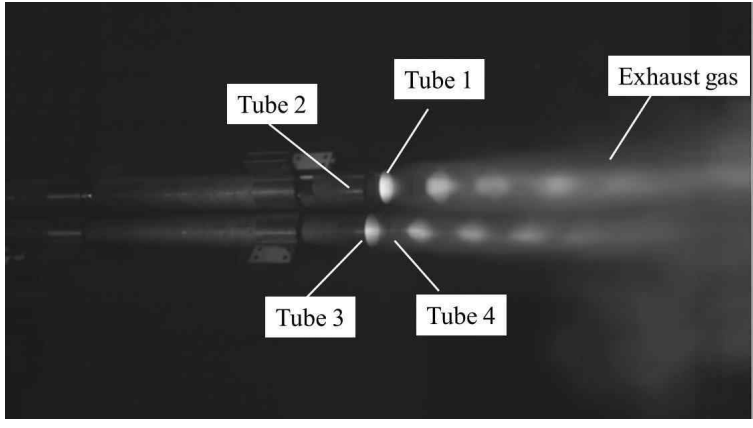

Fig. 14. Photograph of Exit Tube 1 and 3 of the Four-Cyclinder PDRE using $\mathrm{C}_{2} \mathrm{H}_{4}-\mathrm{N}_{2} \mathrm{O}$ Propellant [32]

최근 Matsuoka 등은 Todoroki에서 발전된 형 태로서 4개의 PDE튜브로 구성된 PDR의 발사 시 험을 수행하였다[30]. Fig. 13은 PDR의 구성도와 발사 시험 장면으로써, 캐터펄트 장치를 이용하 여 초기 속도를 얻은 후 엔진을 작동하는 방법으 로 비행 시험하였다. 로켓엔진은 Todoroki와 유 사하게 제어 및 측정 계통, 공급 및 점화 계통 데토네이션 엔진 구간으로 나뉘어 있다. 총 중 량은 $32 \mathrm{~kg}$, 전체 길이는 $1,800 \mathrm{~mm}$ 이며, 이 중 제어 및 공급 계통이 포함된 본체의 길이는 945 $\mathrm{mm}$ 이다. 액체 아산화질소 $\left(\mathrm{N}_{2} \mathrm{O}\right)$, 액체 에틸렌 $\left(\mathrm{C}_{2} \mathrm{H}_{4}\right)$, 헬륨이 각각 산화제, 연료, 퍼지 가스로 사용되었다. 이 연구에서 고주파 작동을 위하여 Matsuoka 등이 다중 튜브용으로 개발한 CRV (Coaxial Rotary Valve)를 도입하였다[31]. 엔진 작동은 헬륨이 처음 $100 \mathrm{~ms}$ 동안 공급되어 에어 모터를 작동하고, 추진제가 공급되어 $1,500 \mathrm{~ms}$ 동안 1쌍씩 순차적으로 $\mathrm{PDE}$ 를 작동한 후 헬륨 이 $100 \mathrm{~ms}$ 동안 공급되어 환기를 시키는 순서로 사이클을 구성한다.

Figure 14는 지상 실험에서 출구 유동을 고속 카메라로 직접 촬영한 사진으로 $\mathrm{PDE}$ 출구의 초 음속 유동을 확인 할 수 있다[32]. Fig. 15는 3번

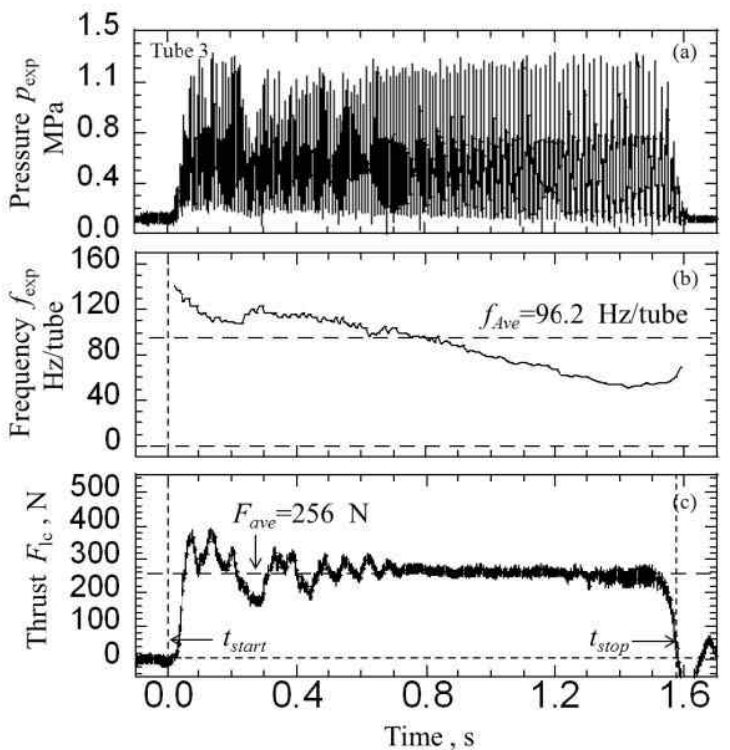

Fig. 15. Time History of Exhaust Pressure, Operation Frequency and Load Cell Output [32]

튜브의 압력변화와, 작동 주파수, 그리고 로드셀 출력으로써, 평균 추력 $256 \mathrm{~N}$, 평균 작동 주파수 가 $96.2 \mathrm{~Hz}$ 임을 도출하였고, 비추력은 $131 \mathrm{sec}$ 으로 얻어졌다. 이 값은 이상적인 비추력 값이 $160 \mathrm{sec}$ 인 것을 감안하면 불완전 연소와 열전달 효과 등을 고려할 때 현실적인 결과로 볼 수 있 다. 비행 시험 계측은 내부에 포함된 가속도계와 고속 카메라는 이용한 외부관측으로 6-자유도 계 측을 수행하였다[30]. 비행 시험의 평균 추력은 $237 \mathrm{~N}$, 비추력 $106 \mathrm{~s}$ 를 도출하였고 데토네이션과 $\mathrm{CRV}$ 에 의한 진동은 비행체에 문제가 되지 않는 것으로 보고하였다. 비행 시험에서 지상 시험에 비하여 다소 낮은 결과가 얻어진 것은 4 번 $\mathrm{PDE}$ 에 수차례 불발(mis-fire) 때문이며 이는 6-자유도 계측 등으로 발사체 기울기 변화 등으로 확인하 였다. 

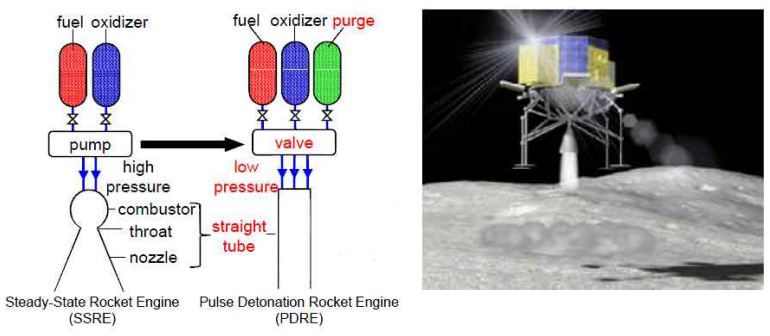

Fig. 16. Concept of PDRE for lunar lander[33]

이들은 JAXA-ISAS의 과제로 Fig. 16과 같이 향 후 SLIM (Smart Lander for Investigating Moon) 프로그램과 같은 미래의 달탐사에 사용될 착륙선의 주엔진으로 $\mathrm{RDE}$ 를 이용하고 $\mathrm{PDE}$ 를 자세제어엔진으로 이용하는 구상을 하고 있다 [33]. 데토네이션 엔진을 소형 탐사선의 엔진으로 사용할 경우 펄스 모드 작동 또는 추력 조절이 필요한 특징 때문에, 정상상태 로켓 엔진에 비하 여 구조가 단순하고 제한 사항이 줄어들어 주엔 진과 자세제어엔진 모두에서 충분한 역할을 할 수 있을 것이라 보고하였다.

\section{5 마이크로 PDE}

과거, 관의 직경이 데토네이션 셀 크기보다 작 은 경우에는 데토네이션이 전파할 수 없는 것으 로 여겨졌으나, 불안정한 상태로 전파 가능함이 실험적으로 밝혀진 이후[34], 추가적인 연구를 통 하여 최근 관의 직경이 작을수록 galloping 데토 네이션의 주파수가 증가함이 확인되었다[35]. 이 러한 가능성을 바탕으로 $\mathrm{Wu}$ 등은 폭이 $\mathrm{mm}$ 이 하인 마이크로 $\mathrm{PDE}$ 를 제작하여 시연하였다 [36,37]. 마이크로 $\mathrm{PDE}$ 는 펄스 모드 작동으로 요 구되는 충격량을 제공하여야 하는 소형 인공위성 의 자세제어 등에서 매우 효율적인 추진기관이 될 수 있을 것으로 여겨진다.

Figure 17은 $\mathrm{Wu}$ 의 마이크로 $\mathrm{PDE}$ 의 평면도와 작동 사진으로써, 연소기는 높이 $1 \mathrm{~mm}$, 너비 0.6 $\mathrm{mm}$, 길이 $100 \mathrm{~mm}$ 이다. 이 그림에서 $\mathrm{P} 1 \sim \mathrm{P} 4$ 는 압력센서 설치 위치이며, $\mathrm{PDE}$ 는 별도의 퍼지가 스 없이 valveless 모드로 작동한다. 단발 데토네 이션 실험에서 $\mathrm{P} 4$ 지점에서 $2 \mathrm{MPa}$ 이상의 최고 압력이 발생하였고, 당량비가 0.5 일 때 $\mathrm{P} 4$ 지점 압력 중 최고 압력이 계측되었다. 또한 데토네이 션 파동의 속도 변화를 통해 DDT는 P2와 P3 지 점 사이에서 발생하는 것을 발견하였다. $100 \mathrm{~Hz}$ 의 연발 데토네이션 작동 시험에서는 연소기 내 부 $60 \mathrm{~mm}$ 근방에서 데토네이션이 발생하였고, $1,900 \mathrm{~m} / \mathrm{s}$ 이상의 연소기 출구 속도를 얻었다. 연발 작동 시험에서 정확한 당량비를 알기 위해

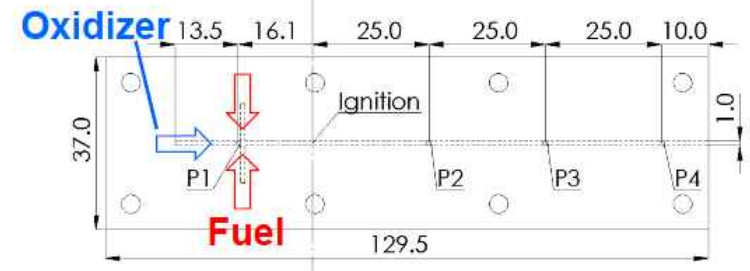

(a) Layout of micro-PDE

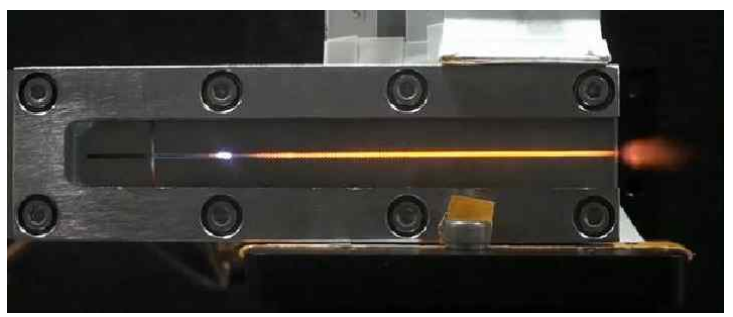

(b) Direct picture of micro-PDE operation

Fig. 17. Micro-PDE by $\mathrm{Wu}[34]$

1 분 동안 연료와 산화제의 소모율을 측정하고, 충격량까지 계산을 하였다.

가시화를 위한 2차원 초소형 연소기 내부에 Shchelkin spiral의 설치가 불가능하기 때문에, 벽면을 톱니모양으로 제작하여 DDT 성능을 비 교하였다. 벽면의 높이는 $0.1,0.18,0.26$ 및 0.29 $\mathrm{mm}$ 로 설정을 하여 실험을 수행하였다. 에틸렌과 산소를 이용한 $100 \mathrm{~Hz}$ 의 고주파수 실험에서 벽 면이 $0.1,0.18 \mathrm{~mm}$ 의 경우 매끈한 경우보다 $\mathrm{DDT}$ 거리가 현저히 줄어듦을 확인한 반면, 0.26 와 $0.29 \mathrm{~mm}$ 는 전파 속도가 $1300 \mathrm{~m} / \mathrm{s}$ 근방으로 기록되어 고속 아음속화염 형태로 발전하였다고 보고하였다.

\subsection{Valveless PDE}

Valveless PDE는 연료와 산화제, 퍼지 가스 등 의 기체의 흐름을 제어하는 밸브가 존재하지 않 는 형태의 PDE이다. Valveless PDE는 퍼지가스, 연료, 산화제의 압력을 다르게 설정하는 방식으 로 별다른 제어 없이 작동 기체의 압력 차이로 기체 주입 시기를 조절하여 고주파로 작동이 가 능하다. Brophy 등은 공기흡입 추진기관으로 이 용하기 위하여 valveless PDE를 연구하였으며 [38], Wang 등도 kerosene-공기를 이용한 연구를 수행하였으나[39], 공기 공급부의 압력이 연소실 압력보다 커야하는 점을 고려하였을 때 PGC 추 진기관으로서 $\mathrm{PDE}$ 장점이 희석되는 측면이 있 다.

한편, Endo 등은 추진기관 부품 등의 고온 표 면처리의 방법으로 솔레노이드 밸브를 장착하지 않은 valveless PDE를 연구하였다[40]. Fig. 18은 


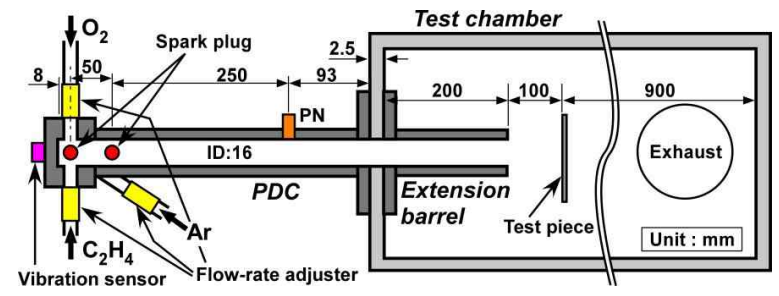

Fig. 18. Arrangement of Experiment on Thermal Spraying[40]

표면처리를 위한 valveless $\mathrm{PDE}$ 의 개요도이다. 작동 주파수는 기체의 압력과 유량제어기(flow rate adjuster) 를 통하여 이루어진다. 유량제어기 는 일종의 오리피스로서 valveless $\mathrm{PDE}$ 의 고주파 작동을 위하여 유체역학적으로 설계된 부품이다. 기체의 압력은 퍼지가스의 압력이 가장 높고, 연 료와 산화제는 동일한 압력으로 설정되었다. 데 토네이션 발생 직후, 모든 가스의 공급이 차단되 며, PDE 내부의 압력 감소하면 퍼지가스가 공급 되어 연소기를 환기시킨 후, 연료와 산화제가 동 시에 주입된다. 튜브 내부가 연료와 산화제로 채 워지면 다시 점화하여 데토네이션을 발생시킨다. 이러한 시스템으로 이들은 $150 \mathrm{~Hz}, 250 \mathrm{~Hz}$ 의 고 주파수를 얻어내었으며 작동시간 또한 $150 \mathrm{~Hz}$ 의 경우 15 분, $250 \mathrm{~Hz}$ 의 경우 20 초로 상당히 긴 시 간동안 작동을 하였음을 보고하였다.

이들은 개발된 시스템을 이용하여 원하는 부품 의 표면에 피막을 형성하는 방법 중 하나인 열 분무기(thermal spray)에 적용한 사례를 보고하 였다. 실험은 Fig. 18 과 같이 $\mathrm{PDE}$ 전방에 판을 설치한 형태로, $\mathrm{PN}$ 으로 표시된 분말 투입노즐을 통하여 코팅재료를 투입하고, 분말이 데토네이션 파의 고온-고속의 유동에 의하여 분사되어 재료 표면에 막을 형성한다. 이들의 연구에서 가스 터 빈 블레이드나 연소기와 같이 고온 코팅이 필요 한 분야에서 기존의 방법에 비하여 높은 품질과 효율의 코팅 결과를 얻을 수 있음을 보고하였다.

\section{IV. 결 론}

본 연구에서는 데토네이션 현상을 추진기관에 효과적으로 이용하기 위한 방법으로써, 국내에서 는 많은 연구가 이루어지지 않은 PDE와 PGC의 개념 및 이론 성능 특징에 대하여 소개하고, 최 근에 진행된 $\mathrm{PDE}$ 활용 추진기관 연구들에 대하 여 소개하였다. 지면 관계로 점화, 공급 계통, 노 즐 등 $\mathrm{PDE}$ 의 요소기술에 대한 내용 및 $\mathrm{RDE}$ 등 새로운 개념의 데토네이션 추진기관에 대한 내용
은 별도의 기회를 통하여 소개하고자 한다.

데토네이션 현상을 이용하는 추진기관은 연소 과정에서 추가적인 압축 효과로 이전에 달성하기 어려웠던 열효율을 달성할 수 있는 연소 방식으 로써 추진기관의 열효율 향상의 측면에서 "game-changer" 로 여겨지고 있다. 높은 이론적 열효율의 달성 가능성만으로도 충분한 연구 가치 를 가지는 연구 대상이라고 여겨져, 전 세계 여 러 기관에서 많은 연구 개발을 수행하여 왔으며 상당한 수준의 기술 발전이 이루어진 상태이다. 그러나 아직 열관리 문제 등 해결하여야 할 기술 적 난제도 존재하며, 전반적인 기술 성숙도가 실 용화 단계에 미치지 않은 상태이므로 후발 주자 에게도 많은 기회가 열려 있는 분야로 여겨진다.

\section{후 기}

논문은 국방과학연구소 국제공동기초연구과제 (ADD-12-70-05-01)과 정부(미래창조과학부)의 지 원으로 한국연구재단 우주핵심기술개발사업 (2013M13A3A02042442)의 지원을 받았습니다. 본 문헌에 이용된 그림은 해당 참고문헌의 전자문서 에서 인용하였습니다.

\section{References}

1) Turns, S.R., An Introduction to Combustion: Concepts and Applications, 3rd Edition, New York, McGraw-Hill, 2011.

2) Heiser, W.H., and Pratt, D.T., "Thermo dynamic Cycle Analysis of Pulse Detonation Engines," Journal of Propulsion and Power, Vol.18, No.1, pp.68-76 2002.

3) Wu, Y., Ma, F., Yang, V., "System Performance and Thermodynamic Cycle Analysis of Airbreathing Pulse Detonation Engines," Journal of Propulsion and Power, Vol. 19, No. 4, 2003, pp.556-567.

4) Zel'Dovich, Ya. B., "On the Theory of Detonation Propagation in Gaseous Systems," Sov. J. Exp. Theor. Phys., Vol. 10, 1940, pp.542 568.

5) Hoffmann, N., "Reaction Propulsion by Intermittent Detonative Combustion", German Ministry of Supply, AI152365 Volkenrode Translation, 1940.

6) Nicholls, J. A., Wilkinson, H. R. and 
Morrison R. B., "Intermittent Detonation as a Thrust-Producing Mechanism," Journal of Jet Propulsion, Vol. 27, No. 5, 1957, pp.534 541.

7) Eidelman S., Grossmann W., and Lottati, I., "A review of Propulsion Applications of the Pulsed Detonation Engine Concept," AIAA 89-2446, 25th Joint Propulsion Conference, Jul. 1989.

8) Bussing, T. R. A., Bratkovich, T. E., and Hinkey Jr., J. B., "Practical Implementation of Pulse Detonations Engines," 33rd Joint Propulsion Conference and Exhibit, Jul. 1997.

9) Kailasanath, K., "Applications of Detonations to Propulsion : A Review," AIAA 99-1067, 37th AIAA Aerospace Sciences Meeting and Exhibit, Jan. 1999.

10) Kailasanath, K., "Review of Propulsion Applications of Detonation Waves," $A I A A$ Journal, Vol. 38, No. 9, Sep. 2000, pp. 1698-1708.

11) Kailasanath, K., "Recent Developments in the Research on Pulse Detonation Engines," AIAA Journal, Vol. 41, No. 2, Feb. 2003, pp. 145-159.

12) Roy, G. D., Frolov, S. M., Borisov, A. A., Netzer, D. W., "Pulse Detonation Propulsion : Challenges, Current Status, and Future Perspective," Progress in Energy and Combustion Science, Vol. 30, May. 2004, pp. 545-672.

13) Wolanski, P., "Detonative Propulsion," Proceedings of the Combustion Institute, Vol. 34, Nov. 2012, pp. 125-158.

14) First Holzwarth Experimental Gas Turbine, 1908, Deutsches Museum.

http://www.deutsches-museum.de/en/collect ions/machines/power-engines/gas-turbines/holz warth-gas-turbine-1908/

15) Gunston, B., "Napier Nomad: An engine of outstanding efficiency," Flight, April 1954, pp.543 - 551, Retrieved 18 December 2009.

16) Barr, L., "Pulse Detonation Engine Flies into History," Press Release, Air Force Material Command, May, 2008.

17) Hinkey, J., Williams, J., Henderson, S., Bussing, T., "Rotary-Valved, Multiple-Cycle, Pulse Detonation Engine Experimental Demonstration," AIAA 1997-2746, 33rd Joint
Propulsion Conference and Exhibit, 1997.

18) Dean, A. J., "A Review of PDE Development for Propulsion Application," AIAA 2007-985, 45th AIAA Aerospace Sciences Meeting and Exhibit, Jan. 2007.

19) Zhang, G.T., Jiang, Y.T., Foo, H.S., Yip, M.S., Falempin, F., and Daniau, E., "First steps for the development and testing of a pulse detonation engine for UAV application," AIAA 2008-2681, May 2008.

20) Kojima, T., Tsuboi, N., Taguchi, H., Kobayashi, H., Sato, T., Daimon, Y., and Inaba, K., "Design Study of Turbine for Pulse Detonation Combustor," AIAA 2007-5081, 43rd AIAA/ASME/SAE/ASEE Joint Propulsion Conference \& Exhibit, Jul. 2007.

21) Kojima, T. and Kobayashi, H., "Analytical and Experimental Study on PDE with Exit Valves for Hypersonic Propulsion System," AIAA 2005-3510, 41st AIAA/ASME/ SAE/ASEE Joint Propulsion Conference \& Exhibit, Jul. 2005.

22) Kasahara, J., Hasegawa, A., Nemoto, T., Yamaguchi, H., Yajima, T., and Kojima, T., "Thrust Demonstration of a Pulse Detonation Rocket "Todoroki", AIAA Paper 2007-5007, July 2007.

23) Bussing. T., "Vulcan Overview," VULCAN Industry Day Agenda, Jun. 10, 2008

24) Schauer, F., and Mabbett, A., "Vulcan Engine Demonstration to Turbine-Drive Experiments," 2011 International Workshop on Detonation for Propulsion (IWDP2011), Nov. 2011.

25) Dean, A. J., Rasheed, A., Tangirala, V., and Pinard, P. F., "Operation and Noise Transmission of an Axial Turbine Driven by a Pulse Detonation Combustor," Proccedings of the ASME Turbo Expo 2005, Jun. 2005.

26) Endo, T., Susa, A., Kanekiyo, K., Hanta, Y., Mitsunobu, A., Takahashi, T., “Development of Pulse Detonation Technology in Valveless Mode and its Application to Turbine-Drive Experiments," 2011 International Workshop on Detonation for Propulsion (IWDP2011), Nov. 2011.

27) Sakurai, T., Uiasa, S., "Development of Pulse Detonation Combustor for $1 \mathrm{~kW}$-Class 
Micro Gas Turbine," 2011 International Workshop on Detonation for Propulsion (IWDP2011), Nov. 2011

28) Glaser, A.J., Caldwell, N., Gutmark, E., "Performance of an Axial Flow Turbine Driven by Multiple Pulse Detonation Combustors," AIAA 2007-1244, 45th AIAA Aerospace Sciencces Meeting and Exhibit, Jan. 2007.

29) Kasahara, J., Hasegawa, A., Nemoto, T. and Yamaguchi, H., "Thrust Demonstration of a Pulse Detonation Rocket "Todoroki"," 43rd AIAA/ASME/SAE/ASEE Joint Propulsion Conference \& Exhibit, Jul. 2007.

30) Matsuoka, K., Takagi, S., Kasahara, J., Morozumi, T., Kashiwazaki, T., Fujiwara, Y., Matsuo, A., and Funaki, I., "Study on a Rotary-Valved Four-Cylinder Pulse Detonation Rocket : Six Degree-of-Freedom Flight Measurement," AIAA 2014-1319, 52nd Aerospace Sciences Meeting, Jan. 2014.

31) Matsuoka, K., Esumi, M., Ikeguchi, K. B., Kasahara, J., Matsuo, A., and Funaki, I., "Optical and Thrust Measurement of a Pulse Detonation Combustor with a Coaxial Rotary Valve," Combustion and Flame, Vol. 159, 2012, pp.1321 132.

32) Morozumi, T., Sakamoto, R., Kashiwazaki, T., Matsuoka, K., Takagi, S., Kasahara, J., Matsuo, A., and Funaki, I., "Study on a Rotar-Valved Four-Cylinder Pulse Detonation Rocket : Thrust Measurement by Ground Test," AIAA 2014-1317, 52nd Aerospace Sciences Meeting, Jan. 2014.

33) Kasahara, J., Matsuoka, K., "Experimental Study on a Four-Cylinder Pulse Detonation Rocket Engine Flight Test Model," 2013 International Workshop on Detonation for
Propulsion (IWDP2013), Jul. 2013

34) Wu, M.H., Burke, M.P., Son, S.F. and Yetter, R.A., "Flame acceleration and the transition to detonation of stoichiometric ethylene/oxygen in microscale tubes," Proceedings of the Combustion Institute, Vol. 31, 2007, pp. 2429-2436.

35) Gao, Y., Lee, J.H.S., and $\mathrm{Ng}, \mathrm{H}$. Dick. "Velocity fluctuation near the detonation limits," Combustion and Flame, 2014, in press. http://dx.doi.org/10.1016/j.combustflame.2014.04.020

36) Wu, M.-H., "Progress in the Development of Pulsed Detonation Microthrusters," 2013 International Workshop on Detonation for Propulsion (IWDP2013), Jul. 2013.

37) Wu, M.-H., and Lu, T.-H. "Development of a chemical microthruster based on pulsed detonation." Journal of Micromechanics and Microengineering Vol.22 (2012) 105040.

38) Brophy, C. M., Werner, LT S., and Sinibaldi, J. O., "Performance Charcterization of a Valveless Pulse Detonation Engine," AIAA 2003-1344, 41st Aerospace Sciences Meeting and Exhibit, Jan. 2003.

39) Wang, Z., Yan, C., Fan, W., Zheng, L., and Qiu, H., "Experimental Study of Kerosene/air Valveless Air-Breathing Pulse Detonation Engines," AIAA 2009-1066, 47th AIAA Aerospace Sciences Meeting Including The New Horizons Forum and Aerospace Exposition, Jan. 2009.

40) Endo, T., "Thermal Spary by Pulsed Detonations," 2013 International Workshop on Detonation for Propulsion (IWDP2013), Jul. 2013. 